\title{
Glucose-6-Phosphatase and a-Glucosidase Inhibitors from Smilax moranensis Roots Identified by Affinity-Directed Fractionation
}

\author{
Daniel Rosas-Ramírez ${ }^{1}$ (D) Sonia Escandón-Rivera ${ }^{2}$ (D) - Adolfo Andrade-Cetto ${ }^{2}$ (D) $\cdot$ Roberto Arreguín-Espinosa $^{1}$ (D)
}

Received: 6 October 2020 / Accepted: 24 November 2020 / Published online: 7 January 2021

(C) Sociedade Brasileira de Farmacognosia 2021

\begin{abstract}
The ethanol/water-soluble extracts of the roots of Smilax moranensis M. Martens \& Galeotti, Smilacaceae, which have been appreciated since pre-Hispanic times and traditionally used to treat type 2 diabetes in Mexico, were fractionated by the application of the affinity-directed method to identify glucose-6-phosphatase and $\alpha$-glucosidase inhibitors. Mass spectrometry was used to identify the inhibitor as free ligands after released from the enzymatic complex by denaturing acidic conditions. The affinity study led to the identification of chlorogenic acid as a glucose-6-phosphatase inhibitor, which is the most abundant metabolite present in the analyzed crude drug. In addition, the affinity studies led to the identification of a flavonolignan glycoside as an $\alpha$ glucosidase inhibitor. In silico analysis with $\alpha$-glucosidase MAL12 from the yeast Saccharomyces cerevisiae allowed to determine the best conformational rearrangement for the $\alpha$-glucosidase inhibitors.
\end{abstract}

Keywords Diabetes $\cdot$ Enzyme inhibitors $\cdot$ Free radical scavenger $\cdot$ Hypoglycemic $\cdot$ Molecular docking $\cdot$ Polyphenols

\section{Introduction}

In Mexico, medicinal plants have traditionally played an important role (Mata-Torres et al. 2020); besides, the renewed worldwide interest in the use of herbal medicines under the belief of their lack of toxicity and their low cost has led to the use of phytopharmaceuticals for the treatment of hyperglycemia. However, very few traditional medicinal plants have been studied to verify their hypoglycemic properties, toxicity, and abundance to ensure a safe source of the medicinal plants. Time-consuming processes for the purification of bioactive natural products limit the performance of a fast and efficient way to identify bioactive molecules in crude extracts, making the isolation of active metabolites laborious. Consequently, it is essential to develop a simple, economical, and efficient method for the analysis of pharmacologically active

Daniel Rosas-Ramírez

dgrosas@unam.mx

1 Departamento de Química de Biomacromoléculas, Instituto de Química, Universidad Nacional Autónoma de México, Ciudad Universitaria, 04360 Mexico City, Mexico

2 Departamento de Biología Celular, Facultad de Ciencias, Universidad Nacional Autónoma de México, Ciudad Universitaria, 04360 Mexico City, Mexico metabolites, like the affinity-directed fractionation-mass spectrometry methods used in the present investigation (Fan et al. 2019; Rosas-Ramírez et al. 2020). Mexico ranks first in the world in childhood obesity, second in adults, and sixth in prevalence of diabetes, one of the main causes of blindness, chronic kidney failure, and non-traumatic amputations (Turnbull et al. 2019), which complicates their medical care when facing an emerging disease, such as COVID-19 (Pal and Bhansali 2020). The prevalence of diabetes in the country is the cause of a national mortality alert.

In the present research, $\alpha$-glucosidase from the yeast Saccharomyces cerevisiae and glucose-6-phosphatase (G6Pase) from liver microsomes of rats were selected as the enzymes; acarbose and chlorogenic acid as the high-affinity inhibitors for positive controls (Fig. S1); and a total ethanol/ water root extract from the traditional-medicinal plant Smilax moranensis M. Martens \& Galeotti, Smilacaceae, as the source of high-affinity inhibitors. These two key enzymes involved in the control of the homeostatic regulation of blood glucose levels with reduction of postprandial glycemic peaks (Ghosh et al. 2002). The hypoglycemic effect on rats of the ethanol/water extract has been previously reported (AndradeCetto 2011; Romo-Pérez et al. 2019; Mata-Torres et al. 2020) and 3-O-caffeoyl-quinic acid, 5-O-caffeoyl-quinic acid, and trans-resveratrol were isolated, which may potentially be involved in this effect (Romo-Pérez et al. 2019). Smilax 
moranensis is native to Mexico, known as sarsaparilla, corresponding to a complex of species of the Smilax genus used in traditional medicine since pre-Columbian times. Besides the use as hypoglycemic, it has expectorant, diuretic, depurative, and anti-inflammatory properties (Andrade-Cetto 2011; Romo-Pérez et al. 2019).

\section{Materials and Methods}

Low-resolution electrospray ionization mass spectrometry (ESI-MS) data were measured in a Bruker Daltonics Esquire 6000 ESI ion trap mass spectrometer. Nitrogen was used as both nebulizing and drying gas. Mass spectra were acquired over the range of $50-1500 \mathrm{~m} / \mathrm{z}$ in $10 \mathrm{~s} / \mathrm{scan}$ using electrospray ionization with a capillary voltage set to $4 \mathrm{kV}$. Direct infusion ESI-MS spectra were deconvoluted using the Bruker Data Analysis software. High-resolution ESI-MS data were measured in a coupled liquid chromatography system with single quadruple mass spectrometry and time of flight (HPLC-EMSQ-TOF Model G6530BA) (Agilent Technologies, Inc., Santa Clara, CA, USA).

The roots of Smilax moranensis M. Martens \& Galeotti, Smilacaceae, were originally collected in Santos Reyes Nopala, Oaxaca, Mexico, in 2011, and a voucher specimen was deposited in the Medicinal Plant Herbarium IMSS (IMSS 15815); for the chemical study, new fresh plant material was collected in the same location on 2013 and its authenticity has been determined by pharmacopeial methodologies and comparison with the authentic samples on deposit at the Herbarium IMSS (Andrade-Cetto 2011). After collection, the powdered dry roots $(0.1 \mathrm{~kg})$ were macerated at $30^{\circ} \mathrm{C}$ in a mixture $(500 \mathrm{ml})$ of $\mathrm{EtOH} / \mathrm{H}_{2} \mathrm{O}(1: 1)$ for $2 \mathrm{~h}$ to give, after removal of the solvents, a dark brown syrup $(2 \mathrm{~g})$.

The affinity-directed fractionation-mass spectrometry methods used in the present investigation were previously described (Rosas-Ramírez et al. 2020). Aliquots $(10 \mu \mathrm{l}$, in triplicates) of the $\mathrm{EtOH} / \mathrm{H}_{2} \mathrm{O}$-soluble extract $(200 \mu \mathrm{g} / \mathrm{ml})$, as well as of chlorogenic acid (positive control for G6Pase) and acarbose (positive control for $\alpha$-glucosidases) at a concentration of $2000 \mu \mathrm{M}$, were independently incubated for $5 \mathrm{~min}$ with $20 \mu \mathrm{l}$ of the enzyme stock solution (Andrade-Cetto and Cárdenas 2010; Rosas-Ramírez et al. 2018, 2020). Upon loading the test samples at the top of the spin-exclusion column, the mixtures were eluted by centrifugation at RCF $42,985 \times \mathrm{g}$ for $4 \mathrm{~min}$; then, the eluate $(50 \mu \mathrm{l})$, corresponding to the solvent front and containing the enzyme-inhibitor complex, was collected and treated as previously described by denaturing acidic conditions (Rosas-Ramírez et al. 2020). They were analyzed by direct flow injection on an ion trap ESI mass spectrometer.

Analytical HPLC analyses were performed on an Agilent 1260 Infinity system equipped with a G1311B quaternary pump, a G1367E auto sampler, and a G1315C DAD. The detector was maintained at 230, 254, 280, 320, and $365 \mathrm{~nm}$. The separation was carried out using a Phenomenex ${ }^{\circledR}$ Luna Polar C-18 $(50 \times 2.1 \mathrm{~mm}$ id., $1.6 \mu \mathrm{m})$ reversed-phase column; the control of the equipment, data acquisition, and processing and management of the chromatographic information were performed by OpenLab CDS ChemStation Edition (20012013) software. The HPLC-DAD conditions for the $\mathrm{EtOH} / \mathrm{H}_{2} \mathrm{O}$-soluble extract and the free ligand from the $\alpha$ glucosidase-EtOH/ $\mathrm{H}_{2} \mathrm{O}$ extract complex were as follows: flow rate of $0.30 \mathrm{ml} / \mathrm{min}$ with water containing $0.1 \%$ formic acid as solvent $\mathrm{A}$ and $\mathrm{CH}_{3} \mathrm{CN}$ as solvent $\mathrm{B}$ using a gradient elution of 94:06 (A:B) at 0-15 $\mathrm{min}, 88: 12(\mathrm{~A}: \mathrm{B})$ at $15-30 \mathrm{~min}, 78: 22$ (A:B) at 30-40 $\mathrm{min}, 70: 30$ at $40-48 \mathrm{~min}, 05: 95(\mathrm{~A}: \mathrm{B})$ at 48 $49 \mathrm{~min}$, and holding for a minute and again returning to the initial conditions 94:06 (A:B) at $35 \mathrm{~min}$. The column temperature was kept at $35^{\circ} \mathrm{C}$. Working solutions for the $\mathrm{EtOH} / \mathrm{H}_{2} \mathrm{O}$ soluble extract were prepared by dissolving $20 \mathrm{mg}$ in $2 \mathrm{ml}$ of a mixture of $\mathrm{MeOH} / \mathrm{H}_{2} \mathrm{O}(1: 1)$. The samples were injected ( $3 \mu \mathrm{l})$ using an autosampler. Chlorogenic acid was identified by comparison using the HPLC retention time, analyzing their absorbance spectrum profile and co-elution experiments.

Docking was carried out with Auto Dock 4.2 software (The Scripps Research Institute, La Jolla, CA, USA) using the default parameters as previously described (Rosas-Ramírez et al. 2018).

\section{Results and Discussion}

Affinity-directed fractionation, through the use of size exclusion chromatography (SEC) on spin column centrifugation for the purification of proteins of therapeutic interest for screening of compound libraries of natural extracts, was applied in combination with ESI-MS for ligand detection (Siegel 2007; Rosas-Ramírez et al. 2020) to identify G6Pase and $\alpha$ glucosidase inhibitors from $S$. moranensis roots. First, rat hepatic G6Pase was selected as the enzyme and chlorogenic acid as a high-affinity inhibitor (Fig. S2). Figure 1 illustrates the LRESI-MS spectra obtained from these SEC/ESI-MS affinity-screening assays: G6Pase, showing the enzyme peaks (Fig. 1a); and the free ligand adduct $(\mathrm{m} / \mathrm{z} 380[\mathrm{M}-\mathrm{O}+$ $\left.\mathrm{C}_{2} \mathrm{H}_{5} \mathrm{~N}\right]^{-}$) from the G6Pase-chlorogenic acid complex after elution in SEC and released by denaturing acidic conditions, where the enhanced inhibitor peak was tracked by the applied SEC/ESI-MS affinity-directed fractionation (Fig. 1b). Thus, this procedure was applied to the $\mathrm{EtOH} / \mathrm{H}_{2} \mathrm{O}$-soluble extract from $S$. moranensis roots; the LRESI-MS of the free ligand adduct from the G6Pase-EtOH/ $\mathrm{H}_{2} \mathrm{O}$ extract complex (Fig. 1c) shows the same peak obtained from the complex G6Pasechlorogenic acid $(\mathrm{m} / \mathrm{z} 380)$, which indicates that chlorogenic acid is the inhibitor of the G6Pase in S. moranensis, besides, it was the only metabolite observed in LRESI-MS after the affinity-directed fractionation. The 26-amu difference 


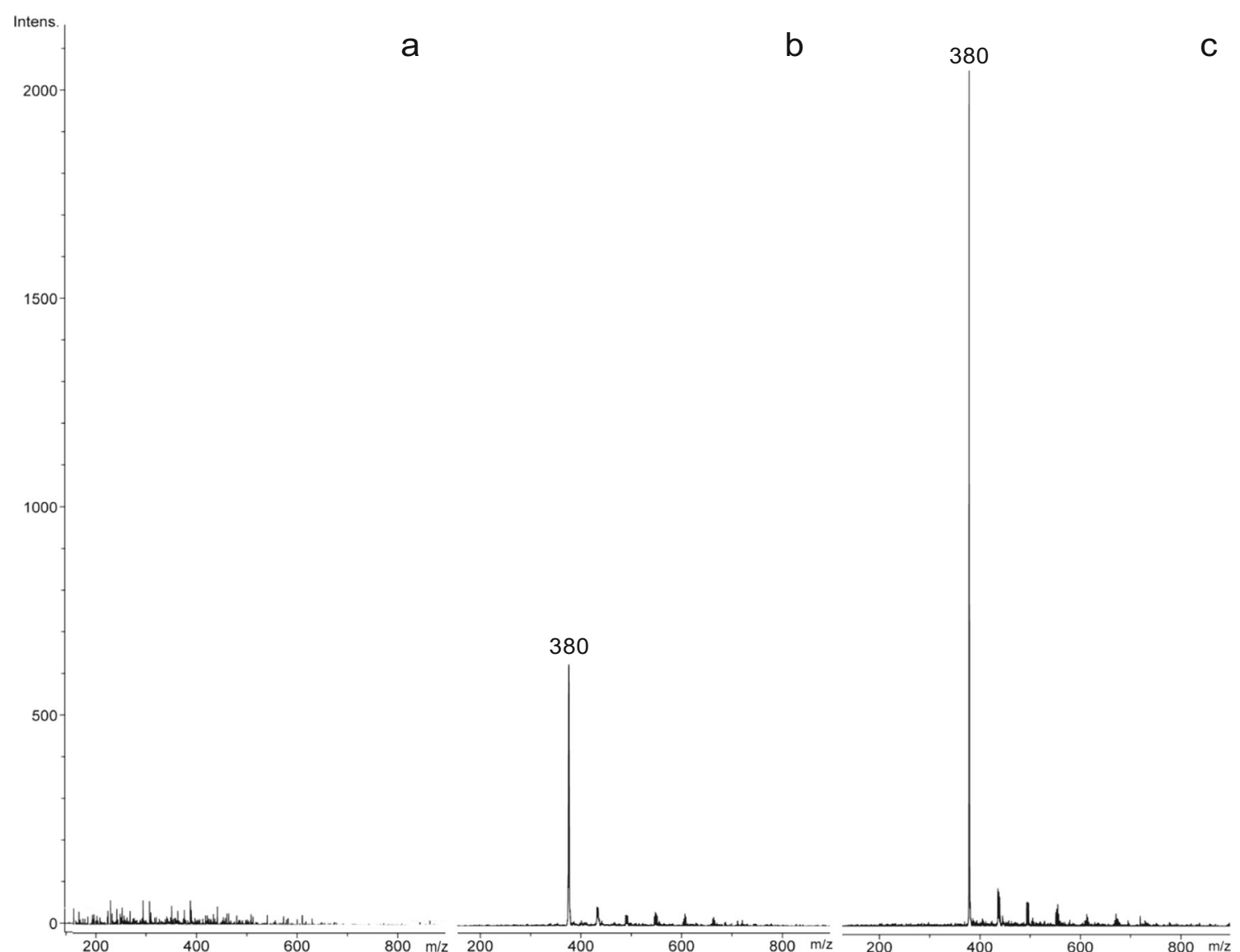

Fig. 1 Low-resolution ESI mass spectra, in negative mode, obtained from the affinity-screening assay for G6Pase from liver microsomes: (a) LRESI-MS of G6Pase, showing the enzyme peaks after affinity assay without inhibitor; (b) LRESI-MS of free ligand adduct (chlorogenic acid, $\mathrm{C}_{16} \mathrm{H}_{18} \mathrm{O}_{9}$ plus amine group: $m / z, 380\left[\mathrm{M}-\mathrm{O}+\mathrm{C}_{2} \mathrm{H}_{5} \mathrm{~N}\right]^{-}, \mathrm{C}_{18} \mathrm{H}_{23} \mathrm{O}_{8} \mathrm{~N}-$
H) from the G6Pase-chlorogenic acid complex by the applied affinityscreening assay; (c) LRESI-MS of free ligand $(\mathrm{m} / \mathrm{z}$ 379) from the G6Paseethanol/water extract complex, showing the inhibitor peak tracked by the applied affinity-screening assay between the $\mathrm{m} / \mathrm{z}$ peak of the chlorogenic acid alone $(\mathrm{m} / \mathrm{z} 353$ $\left.[\mathrm{M}-\mathrm{H}]^{-} ; \mathrm{C}_{16} \mathrm{H}_{18} \mathrm{O}_{9}-\mathrm{H}\right)$ and the $m / z 380$ peak of the G6Pasechlorogenic acid complex (Fig. S2), after elution in SEC and released by denaturing acidic conditions, indicates the formation of a Schiff base adduct with an amine residue in lateral protein chains such as alanine (Fig. S3), as previously proposed for the irreversible inhibition of this enzyme (Arion et al. 1997). HPLC analysis was carried out with the $\mathrm{EtOH} / \mathrm{H}_{2} \mathrm{O}$ extract and the chromatographic profile indicated that the chlorogenic acid is the main metabolite present in the extract (Fig. S4a). Extensive investigations of the interactions of chlorogenic acid with the components of the rat hepatic G6Pase system determined that binding of chlorogenic acid is freely reversible with G6P-specific translocase T1 (Arion et al. 1997), which mediates diffusion of the G6P through the membrane. G6Pase catalyzes the terminal reaction of glycogenolysis and gluconeogenesis, the two glucose-producing pathways in the liver of humans and higher animals (Arion et al. 1997). G6Pase is widely held to be a significant factor in the abnormally high rates of hepatic glucose production observed in the diabetic state (Mata-Torres et al. 2020).

For the affinity-screening assay of $\alpha$-glucosidase from $S$. cerevisiae, Fig. 2 illustrates LRESI-MS obtained from these SEC/ESI-MS affinity-screening assays: LRESI-MS of the free ligand (acarbose $\mathrm{C}_{25} \mathrm{H}_{43} \mathrm{NO}_{18} \mathrm{Na}: m / z 668[\mathrm{M}+\mathrm{Na}]^{+}$) from the $\alpha$-glucosidase-acarbose complex (Fig. 2a), high-resolution ESI-MS obtained of the free ligand $\left(\mathrm{m} / \mathrm{z}, 689.2044[\mathrm{M}+\mathrm{H}]^{+}\right.$; $\delta=-4.7 \mathrm{ppm}$ ) from the $\alpha$-glucosidase-ethanol/water extract complex showed the inhibitor peak (Fig. 2b). Other minor signals observed are related to $[\mathrm{M}+\mathrm{Na}]^{+}$and $[\mathrm{M}+\mathrm{K}]^{+}$ions of the inhibitor, $m / z, 711.4189$ and 727.1639 , respectively. Five isomeric flavonolignan glycosides with the same molecular weight of $688 \mathrm{~g} / \mathrm{mol}\left(\mathrm{C}_{33} \mathrm{H}_{36} \mathrm{O}_{16}\right)$ have previously been reported (Fig. S5): flavonolignans diastereoisomeric of tricin 4'-O-(erythro- $\beta$-guaiacylglyceryl) ether 7-O-glucoside and tricin 4'-O-(threo- $\beta$-guaiacylglyceryl) ether 7-O-glucosides, from leaves of Hyparrhenia hirta (Bouaziz et al. 2002); diastereoisomeric tricin 4'-O-(threo- $\beta$-guaiacylglyceryl) ether 
Fig. 2 Low-resolution ESI mass spectra obtained from SEC/ESIMS affinity-screening assay for intestinal acetone powder from rats and $\alpha$-glucosidase from yeast. (a) LRESI-MS of free ligand (acarbose $\mathrm{C}_{25} \mathrm{H}_{43} \mathrm{NO}_{18} \mathrm{Na}$ : $m / z 668[\mathrm{M}+\mathrm{Na}]^{+}$) from the $\alpha-$ glucosidase-acarbose complex, by the applied affinity-screening assay intestinal acetone powder from rats. (b) HRESI-MS spectra of free ligand $(\mathrm{m} / \mathrm{z} 689.2044[\mathrm{M}+$ $\mathrm{H}]^{+}$) from the $\alpha$-glucosidase-ethanol/water extract complex, by the applied affinity-screening assay with $\alpha$-glucosidase from Saccharomyces cerevisiae

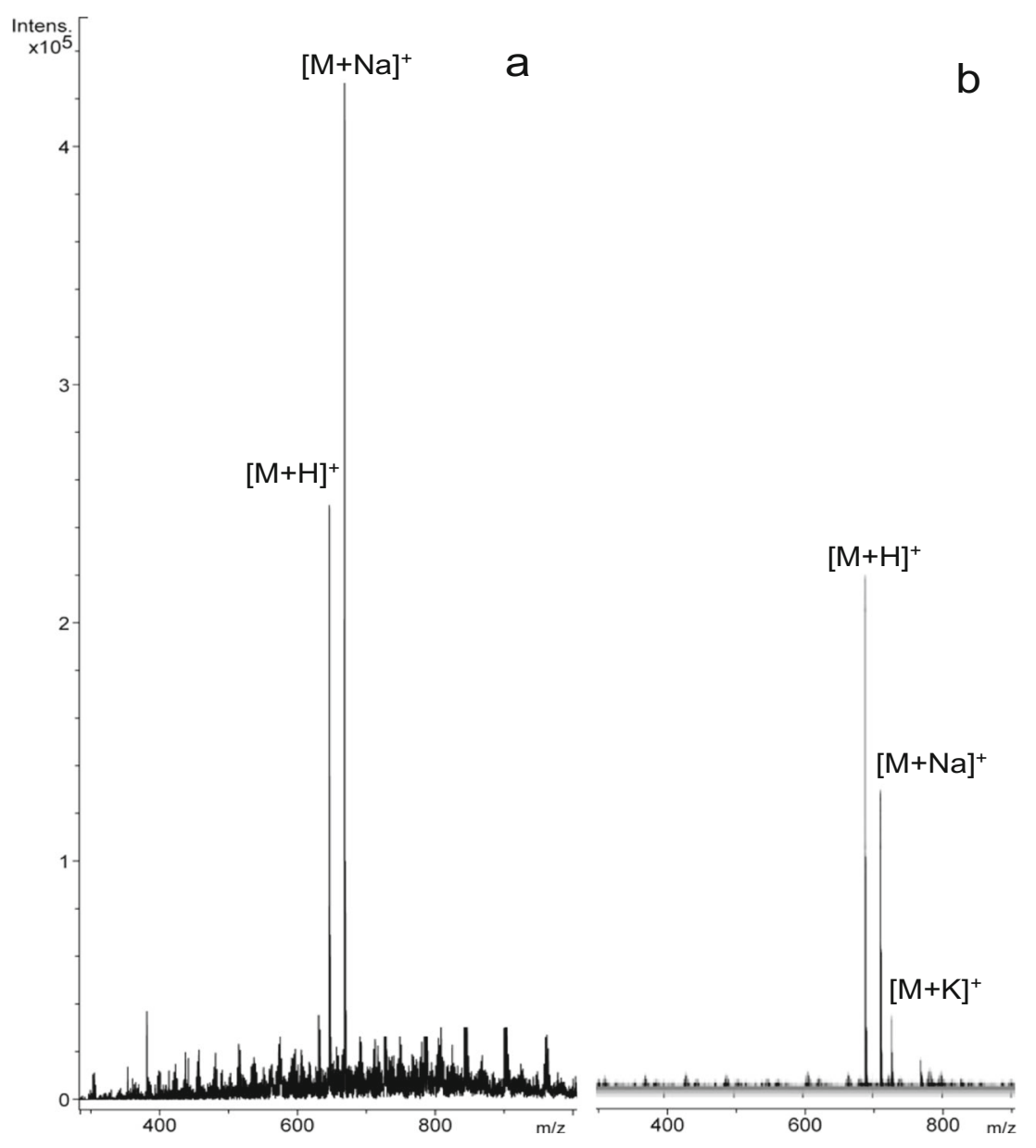

together with their 7"-O-glucosides, from leaves of Zizania latifolia (Lee et al. 2015); and the isomer tricin $4^{\prime}$ $O$-(erythro- $\beta$-guaiacylglyceryl) ether $9 "-O-\beta$-Dglucopyranoside from the aerial parts of Oryza sativa (Yang et al. 2014). Affinity-screening assays coupled off-line to HPLC (Fig. S4b) were used to analyze their absorbance spectrum profiles of the high-affinity compound $\left(R_{\mathrm{t}} 38.70 \mathrm{~min}\right.$, water containing $0.1 \%$ formic acid $/ \mathrm{CH}_{3} \mathrm{CN}$ (94:06) UV $\lambda_{\text {max }}: \mathrm{nm}$ : $(242,278$, and 326$)$, revealing that they correspond to this class of flavonolignans (Bouaziz et al. 2002; Yang et al. 2014; Lee et al. 2015). However, more studies are required to verify the structure. The flavonolignans observed were analyzed by docking studies and a high affinity for the active site was observed, finding greater interaction of tricin $4^{\prime}$ (erythro and threo)-7-O-glucoside with the $\alpha$-glucosidase enzyme.

Docking studies were carried out to improve our understanding of the interaction of active compounds inside MAL12, which was selected as the template for molecular modeling to establish a comparison between the results from the affinity-screening assay and the theoretical inhibition constant $(K \mathrm{i})$ obtained from in silico studies. Ligand-receptor molecular models were calculated for chlorogenic acid and acarbose, previously reported inhibitors of $\alpha$-glucosidase (Arion et al. 1997; Playford et al. 2013), to test the adopted protocol with the $\alpha$-glucosidase template (Fig. S6). The first analysis predicted that acarbose and tricin $4^{\prime}$ (erythro and threo)-7-O-glucoside fit well in the catalytic pocket in the hypothesized binding model and showed hydrogen-bonding interactions with the amino acid residues His279 (1.94 $\AA$ ) and Gln322 (1.71 and $2.19 \AA$ ) for acarbose (Fig. S6), Ser156 $(2.71 \AA)$ and $\mathrm{G} \ln 322(2.01 \AA)$ for tricin 4 '-erythro 7-O-glucoside, and His279 (1.92 $\AA$ ) and Ser308 (1.82 $\AA$ ) for tricin $4^{\prime}$ threo-7-O-glucoside. Chlorogenic acid formed hydrogen bonds in a different place from the active site in MAL12 (Fig. S6) with Lys155 (2.14 ̊), Asp429 (2.08 ̊), and Phe430 (1.85 $\AA$ ). Optimized docking results using MAL12 with tricin 4'(erythro and threo)-7-O-glucoside showed hydrogen-bonding interactions with the amino acid residues

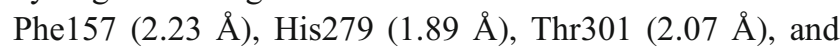
Arg312 (2.02 $\AA$ ) for tricin 4'-erythro-7-O-glucoside, and His279 (1.91 and $2.11 \AA), \operatorname{Asp} 282$ (2.00 ̊), Glu304 (1.98 $\AA$ ), and Ser329 (1.71 $\AA$ ) for tricin 4'-threo-7-O-glucoside (Fig. 3). The theoretical inhibition constant (Ki) was $33.29 \mu \mathrm{M}$ for tricin $4^{\prime}$-erythro and $39.93 \mu \mathrm{M}$ for tricin $4^{\prime}$ - 
Fig. 3 Docking results using the structural model of $\alpha$-Dglucosidase (MAL12) from Saccharomyces cerevisiae, which comprises the catalytic site of the enzyme and the binding interactions for tricin 4'-erythro-7-Oglucoside (gray) with the residues Phe157, His279, Trh301, and $\operatorname{Arg} 312$, and for tricin 4'-threo-7$O$-glucoside (orange) with the residues His279, Asp282, Glu304, and Ser308
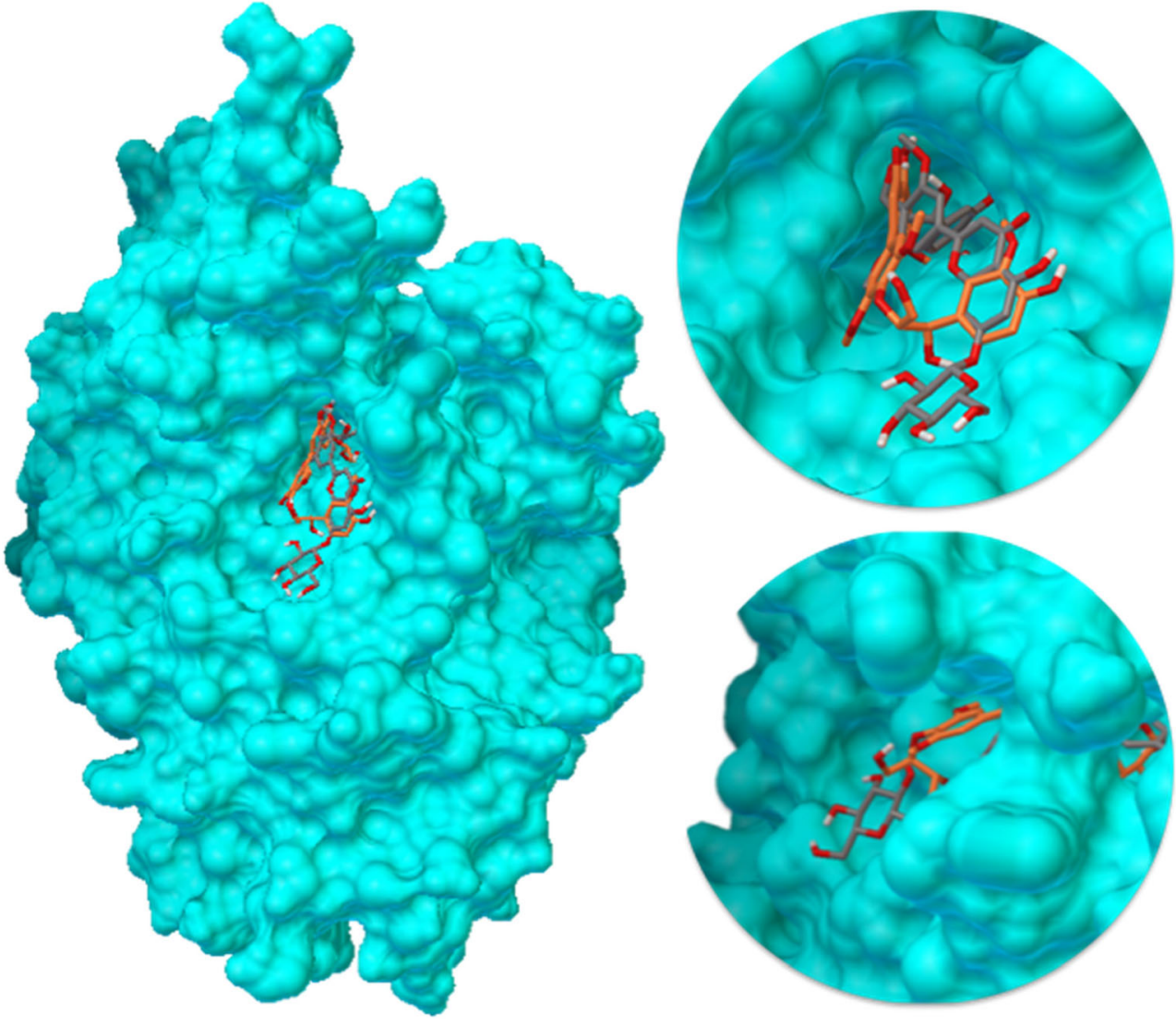

threo. Based on the theoretical docking results for chlorogenic acid, the binding site was situated in a place away from the active site of the template selected for molecular modeling, and projection corresponded to the non-competitive inhibition mode (Pérez-Nájera et al. 2018). The theoretical inhibition constant (Ki) for the chlorogenic acid showed the largest inhibition constant of $135.73 \mathrm{mM}$ for MAL12 in comparison with acarbose $(51.4 \mathrm{nM})$ and the diastereosiomers of tricin $4^{\prime}$ $O$-(erythro/threo- $\beta$-guaiacylglyceryl) ether 7-O-glucoside.

The identification of flavonolignans contributed to expand the knowledge of the active $\alpha$-glucosidase inhibitors present in the decoctions of sarsaparilla (Smilax moranensis) used to treat hyperglycemia, since previous studies only identified as the major therapeutical marker the well-known chlorogenic acid (Andrade-Cetto 2011; Romo-Pérez et al. 2019). Note that the pharmacological potential of the analyzed plant material is probably due to the capability of polyphenols to interact with important cellular processes in which key enzymes such as cyclooxygenase, lipooxygenase, phospholipase $\mathrm{A}_{2}$, NADHoxidase, or glutathione reductase are involved. Catechols in polyphenols are also able to form chelates with metals and are reactive in their oxidized form (like quinonas) with nucleophiles present in lateral protein chains such as cysteine and lysine. Therefore, further in vivo studies with the dereplicated flavonolignans are needed to understand if they can be used as novel $\alpha$-glucosidase inhibitors.
Supplementary Information The online version contains supplementary material available at https://doi.org/10.1007/s43450-020-00116-3.

Acknowledgments DR-R. is grateful to Consejo Nacional de Ciencia y Tecnología for his postdoctoral scholarship (CONACyT-Retenciones 2019-1, 205045). We thank M.Sc. Lucía del Carmen Márquez Alonso (Instituto de Química, UNAM) for support during the recording of mass spectra. The authors are grateful to Professor Rogelio Pereda-Miranda, Editor-in-Chief of Revista Brasileira de Farmacognosia, for his help in the interpretation of the results and his constructive comments for improving the original manuscript.

Authors' Contribution DRR designed the study and performed the affinity-directed fractionation studies, SEC-EM experiments, in vitro inhibitory enzymatic assays, and molecular docking, as well as elaborated the first draft of the manuscript. SER performed the HPLC analysis and supervised the bioassays and molecular docking. AAC designed and supervised bioassays, supervised HPLC methods, and provided laboratory instrumentation and supplies. RAE designed and supervised bioassays, and provided laboratory instrumentation and supplies. All of the authors have read the final manuscript and approved the submission.

Funding Funding was provided by Dirección General de Asuntos del Personal Académico, Programa de Apoyo a Proyectos de Investigación e Innovación Tecnológica, Universidad Nacional Autónoma de México (grants IG20021 and partially by IN226719).

\section{Compliance with Ethical Standards}

Conflict of Interest The authors declare that they have no conflicts of interest. 


\section{References}

Andrade-Cetto A (2011) Hypoglycemic effect of Smilax moranensis root on N5-STZ diabetic rats. Pharmacologyonline 1:111-115

Andrade-Cetto A, Cárdenas R (2010) Gluconeogenesis inhibition and phytochemical composition of two Cecropia species. J Ethnopharmacol 130:93-97. https://doi.org/10.1016/j.jep.2010.04.016

Arion WJ, Canfield WK, Ramos FC, Schindler PW, Burger HJ, Hemmerle H, Schubert G, Below P, Herling AW (1997) Chlorogenic acid and hydroxynitrobenzaldehyde: new inhibitors of hepatic glucose 6-phosphatase. Arch Biochem Biophys 339: 315-322. https://doi.org/10.1006/abbi.1996.9874

Bouaziz M, Veitch N, Grayer R, Simmonds M, Damak M (2002) Flavonolignans from Hyparrhenia hirta. Phytochemistry 60:515520. https://doi.org/10.1016/S0031-9422(02)00145-0

Fan M, Chen G, Sun B, Wu J, Li N, Sarker SD, Nahar L, Guo M (2019) Screening for natural inhibitors of human topoisomerases from medicinal plants with bio-affinity ultrafiltration and LC-MS. Phytochem Rev 19:1231-1261. https://doi.org/10.1007/s11101019-09635-x

Ghosh A, Shieh JJ, Pan CJ, Sun MS, Chou JY (2002) The catalytic center of glucose-6-phosphatase. HIS176 is the nucleophile forming the phosphohistidine-enzyme intermediate during catalysis. J Biol Chem 277:32837-32842. https://doi.org/10.1074/jbc.M201853200

Lee SS, Baek NI, Baek YS, Chung DK, Song MC, Bang MH (2015) New flavonolignan glycosides from the aerial parts of Zizania latifolia. Molecules 20:5616-5624. https://doi.org/10.3390/ molecules20045616

Mata-Torres G, Andrade-Cetto A, Espinoza-Hernández FA, CárdenasVázquez R (2020) Hepatic glucose output inhibition by Mexican plants used in the treatment of type 2 diabetes. Front Pharmacol 11. https://doi.org/10.3389/fphar.2020.00215

Pal R, Bhansali A (2020) COVID-19, diabetes mellitus and ACE2: the conundrum. Diabetes Res Clin Pract 162:108132. https://doi.org/10. 1016/j.diabres.2020.108132

Pérez-Nájera VC, Gutiérrez-Uribe JA, Antunes-Ricardo M, HidalgoFigueroa S, Del-Toro-Sánchez CL, Salazar-Olivo LA, LugoCervantes E (2018) Smilax aristolochiifolia root extract and its compounds chlorogenic acid and astilbin inhibit the activity of $\alpha$ amylase and $\alpha$-glucosidase enzymes. Evid Based Complement Alternat Med 2018:1-12. https://doi.org/10.1155/2018/6247306

Playford RJ, Pither C, Gao R, Middleton SJ (2013) Use of the alphaglucosidase inhibitor acarbose in patients with 'Middleton syndrome': normal gastric anatomy but with accelerated gastric emptying causing postprandial reactive hypoglycemia and diarrhea. Can J Gastroenterol 27:403-404. https://doi.org/10.1155/2013/791803

Romo-Pérez A, Escandón-Rivera S, Andrade-Cetto A (2019) Chronic hypoglycemic effect and phytochemical composition of Smilax moranensis roots. Rev Bras Farmacogn 29:246-253. https://doi. org/10.1016/j.bjp.2019.02.007

Rosas-Ramírez D, Escandón-Rivera S, Pereda-Miranda R (2018) Morning glory resin glycosides as $\alpha$-glucosidase inhibitors: in vitro and in silico analysis. Phytochemistry 148:39-47. https://doi.org/10. 1016/j.phytochem.2018.01.012

Rosas-Ramírez D, Pereda-Miranda R, Escandón-Rivera S, ArreguínEspinosa R (2020) Identification of $\alpha$-glucosidase inhibitors from Ipomoea alba by affinity-directed fractionation-mass spectrometry. Rev Bras Farmacogn 30:336-345. https://doi.org/10.1007/s43450020-00068-8

Siegel MM (2007) Drug screening using gel permeation chromatography spin columns coupled with ESI-MS. In: Wanner KT, Höfner G (eds) Mass spectrometry in medicinal chemistry: applications in drug discovery. Wiley-VCH Verlag GmbH \& Co, KGaA, Weinheim, pp 65-120. https://doi.org/10.1002/9783527610907.ch2

Turnbull B, Gordon SF, Martínez-Andrade GO, González-Unzaga M (2019) Childhood obesity in Mexico: a critical analysis of the environmental factors, behaviors and discourses contributing to the epidemic. Health Psychol Open 6:2055102919849406. https://doi.org/ $10.1177 / 2055102919849406$

Yang Z, Nakabayashi R, Okazaki Y, Mori T, Takamatsu S, Kitanaka S, Kikuchi J, Saito K (2014) Toward better annotation in plant metabolomics: isolation and structure elucidation of 36 specialized metabolites from Oryza sativa (rice) by using MS/MS and NMR analyses. Metabolomics 10:543-555. https://doi.org/10.1007/s11306013-0619-5 